\title{
Gender Differences in the Accuracy of Dobufamine Stress Echocardiography for the Diagnosis of Coronary Artery Disease
}

\author{
Abdou Elhendy, MD, PhD, Marcel L. Geleijnse, MD, Ron T. van Domburg, MSc, \\ Peter R. Nierop, MD, Don Poldermans, MD, PhD, Jeroen J. Bax, MD, PhD, \\ Folkert J. TenCate, MD, PhD, Youssef F.M. Nosir, MD, M. Mohsen Ibrahim, MD, \\ and Jos R.T.C. Roelandt, MD, PhD
}

The accuracy of dobutamine stress echocardiography (DSE) for the diagnosis of coronary artery disease (CAD) has not been yet evaluated in women. We studied the effect of gender on the accuracy of DSE for the diagnosis of CAD in 306 consecutive patients $(210$ men and 96 women) with limited exercise capacity and suspected myocardial ischemia who underwent coronary angiography within 3 months of DSE. There were no serious complications during DSE. Men had a higher prevalence of nonsustained ventricular tachycardia $(7 \%$ vs $0.03 \%$, $p$ $<0.05)$ and supraventricular tachycardia $(9 \%$ vs $0.03 \%$, $p<0.05)$ during the test compared with women. Peak stress rate-pressure product was not different in men and women $(18,140 \pm 4,187$ vs $18,543 \pm 4,223)$. Significant CAD ( $\geq 50 \%$ luminal diameter stenosis) was present in 171 men $(81 \%)$ and in 62 women $165 \%$, p $<0.005)$. The sensitivity, specificity, and accuracy of

ב xercise echocardiography has been reported as an accurate and cost-effective method for the diagnosis of coronary artery disease (CAD) in women. ${ }^{1-5}$ In patients with limited exercise capacity, dobutamine stress echocardiography (DSE) is a feasible alternative. ${ }^{6,7}$ The induction of myocardial ischemia at highdose dobutamine is due to an increase in myocardial oxygen demand, and therefore the test is considered to be a stress modality that simulates exercise. ${ }^{8,9}$ It may be speculated that the high accuracy of exercise echocardiography in women also applies to DSE. However, there are no data to prove this theory. In contrast, it was reported that most of the false-positive DSE tests occur in women. ${ }^{10}$ The aim of this study is to determine if there is a gender difference in the accuracy of DSE for the diagnosis of CAD in patients with limited exercise capacity undergoing DSE for evaluation of myocardial ischemia.

\section{METHODS}

Patient population: The study population comprised 306 consecutive patients with limited exercise capac-

\footnotetext{
From the Thoraxcenter, University Hospital-Dijkzigt, Erasmus University, Rotterdam, The Netherlands. This study was supported in part by the Department of Cardiology, Cairo University Hospital, Cairo, Egypt and by a grant from The Netherlands Organization of Foreign International Cooperation in Higher Education (NUFFIC), The Hague, The Netherlands. Manuscript received April 30, 1997; revised manuscript received and accepted September 5, 1997.

Address for reprints: Abdou Elhendy, MD, PhD, Thoraxcenter, Ba 302, Dr Molewaterplein 40, 3015 GD Rotterdam, The Netherlands.
}

ischemic pattern at DSE for the diagnosis of significant CAD were $76 \%$ (confidence interval [CI] 67 to 84 ), $94 \%$ (Cl 89 to 99 ), and $82 \%$ (Cl 75 to 90 ) in women and $73 \%$ (Cl 67 to 79), 77\% (Cl 71 to 83), and 74\% (Cl 68 to 80) in men, respectively. Overall specificity was higher in women than in men ( $p<0.05$ ). Regional accuracy of DSE was significantly higher in women than in men in the 3 arterial regions $(84 \%$ [Cl 79 to 88 ] vs $75 \%$ [Cl 72 to 79], $p<0.005$ ). It is concluded that DSE is a safe and feasible method for the diagnosis of CAD in women. The overall specificity and the regional accuracy of DSE are higher in women than in men. Further studies are required to evaluate the functional significance of these findings and their reproducibility in different patient populations. (c) 1997 by Excerpta Medica, Inc.

(Am J Cardiol 1997;80:1414-1418)

ity who underwent DSE for evaluation of myocardial ischemia and coronary angiography within 3 months from DSE. Mean age was $58 \pm 12$ years. There were 210 men and 96 women; 214 patients $(70 \%)$ had had a previous myocardial infarction. Clinical characteristics and reasons for stress testing in men and women are shown in Table I. Among the 92 patients without previous myocardial infarction, 5 women (11\%) and 2 men $(4 \%)$ had a low-pretest probability of CAD $(<10 \%), 25$ women $(56 \%)$ and 28 men $(60 \%)$ had an intermediate probability (10\% to $80 \%)$, and 15 women $(33 \%)$ and 17 men $(36 \%)$ had a high probability $(>80 \%)$ using specific calculations based on age, sex, and chest pain characteristics reported by Diamond and Forrester. ${ }^{11}$

Dobutamine stress test: Dobutamine was infused through an antecubital vein starting at a dose of 5 $\mu \mathrm{g} / \mathrm{kg} / \mathrm{min}$ followed by $10 \mu \mathrm{g} / \mathrm{kg} / \mathrm{min}$ (3-minute stages) and increasing by $10 \mu \mathrm{g} / \mathrm{kg} / \mathrm{min}$ every $3 \mathrm{~min}$ utes to a maximum of $40 \mu \mathrm{g} / \mathrm{kg} / \mathrm{min}$. Atropine (up to $1 \mathrm{mg}$ ) was given to patients not achieving $85 \%$ of ageand gender-predicted maximum heart rate at peak dobutamine dose. ${ }^{12}$ The test was interrupted if severe chest pain, ST-segment depression $>2 \mathrm{~mm}$, significant ventricular or supraventricular arrhythmia, hypertension, a systolic blood pressure decrease $>40 \mathrm{~mm}$ $\mathrm{Hg}$, or any intolerable side effect occurred during the test. Ischemia during the electrocardiogram was defined as $\geq 0.1 \mathrm{mV}$ horizontal or downsloping STsegment depression $80 \mathrm{~ms}$ from the $\mathrm{J}$ point compared 


\begin{tabular}{|c|c|c|c|}
\hline Clinical Features & $\begin{array}{c}\text { Men } \\
(n=210)\end{array}$ & $\begin{array}{c}\text { Women } \\
(\mathrm{n}=96)\end{array}$ & $\mathrm{p}$ Value \\
\hline Age (yrs) & $58 \pm 9$ & $58 \pm 13$ & NS \\
\hline Previous MI & $163(78)$ & $51(53)$ & $<0.0001$ \\
\hline Body weight (kg) & $80 \pm 14$ & $68 \pm 11$ & $<0.00001$ \\
\hline Indications for stress testing & & & \\
\hline Typical chest pain & $98(47)$ & 34 (35) & 0.07 \\
\hline Atypical chest pain & $51(24)$ & 37 (39) & $<0.05$ \\
\hline Routine post-Ml assessment & $36(17)$ & 13 (14) & NS \\
\hline To assess revascularization & 25 (12) & 12 (13) & NS \\
\hline \multicolumn{4}{|l|}{ Medications } \\
\hline$\beta$ blockers & $76(36)$ & $43(45)$ & NS \\
\hline Calcium channel blockers & 99 (47) & $48(50)$ & NS \\
\hline Nitrates & $116(55)$ & $46(48)$ & NS \\
\hline ACE inhibitors & 98 (47) & $27(28)$ & $<0.005$ \\
\hline
\end{tabular}

with baseline level or $\geq 0.1 \mathrm{mV} \mathrm{ST-segment} \mathrm{elevation}$ in electrocardiographic leads corresponding to segments without wall motion abnormalities at rest. ${ }^{13}$

Stress echocardiography: Echocardiographic images were acquired from standard views at rest and during stress and recovery. The left ventricular wall was divided into 16 segments and scored using a 4-point scale, where $1=$ normal, 2 = hypokinesia, 3 akinesia, and $4=$ dyskinesia. Wall motion score index was derived by dividing the sum of the score of the 16 segments by 16 . Ischemia was defined as new or worsened wall motion abnormalities. Ischemia was not considered if akinetic segments at rest became dyskinetic during stress. ${ }^{14}$ The echocardiograms were recorded on videotapes and digitized on optical disk (Vingmed, CFM 800, Vingmed Sound A/S, Horten, Norway). Images were compared side by side in quadscreen format by 2 independent observers without the knowledge of the patients' gender, clinical, or angiographic data. In case of disagreement, a majority decision was achieved by a third investigator. The interand intraobserver agreement for dobutamine stress echocardiographic assessment in our laboratory were $91 \%$ and $92 \%$, respectively. ${ }^{15}$

Coronary angiography: Coronary angiography was performed within 3 months of DSE. Significant CAD was defined as a diameter stenosis $\geq 50 \%$ in $\geq 1$ major epicardial arteries by the quantitative method described previously. ${ }^{16}$ Coronary arteries were assigned to myocardial segments as previously described. ${ }^{17} \mathrm{Be}-$ cause of the frequent vascular overlap in the posterior and inferior walls, these 2 regions were assigned to both the left circumflex and the right coronary arteries. ${ }^{18}$

Statistical analysis: Unless specified, data are presented as mean values $\pm \mathrm{SD}$. The chi-square test was used to compare differences between proportions. The Student's $t$ test was used for analysis of continuous data. A $p$ value $<0.05$ was considered statistically significant. Sensitivity, specificity, and accuracy were derived according to the standard definitions and were represented with $95 \%$ confidence intervals $(95 \% \mathrm{CI})$.

\section{RESULTS}

The clinical characteristics of the subjects are shown in Table I. Hemodynamic data are demonstrated in Table II. Dobutamine-atropine induced a significant increase in heart rate $(\mathrm{p}<0.00001)$, systolic blood pressure $(\mathrm{p}<0.0001)$, and rate-pressure product $(\mathrm{p}<0.00001)$ in men and women. Heart rate, systolic blood pressure, and rate-pressure products were not different between men and women at rest or at peak stress. Women received a lower maximum dose of dobutamine and received atropine less frequently than men. Reasons for termination of the test are listed in Table III. The target heart rate was reached more frequently in women. The test was terminated before reaching the maximum dose more frequently in men because of the higher prevalence of angina, ST-segment depression, and arrhythmias necessitating termination of the test in men. Side effects and arrhythmias during the test are shown in Table IV. Supraventricular and ventricular tachycardia occurred more frequently in men. The incidence of hypotension and other side effects was similar in men and women.

Coronary angiography: Significant CAD was detected in 233 patients (76\%). Ninety-one patients (30\%) had single-vessel CAD, 73 (24\%) had 2-vessel CAD, and $69(23 \%)$ had 3-vessel CAD. Normal coronary arteries or $<50 \%$ lesions were present in 73 patients $(24 \%)$. Left anterior descending (LAD) coronary artery stenosis was present in 164 patients (54\%), left circumflex (LCX) stenosis in 133 patients $(43 \%)$, and right coronary artery (RCA) stenosis in 147 patients $(48 \%)$. Men had a higher prevalence of CAD $(81 \%$ vs $65 \%, \mathrm{p}<0.005)$ and multivessel CAD $(55 \%$ vs $27 \%, \mathrm{p}<0.00005)$.

Stress echocardiography: Wall motion score index was higher in men than in women at rest $(1.59 \pm 0.46$ vs $1.40 \pm 0.46, \mathrm{p}<0.005)$ and at peak stress $(1.76 \pm$ 0.53 vs $1.49 \pm 0.52, p<0.0005)$. In patients without previous myocardial infarction, the sensitivity, specificity, and accuracy of DSE in men were $72 \%$ (CI 59 to 85 ), $67 \%$ (CI 53 to 80 ), and $70 \%$ (CI 57 to 83 ). The sensitivity, specificity, and accuracy in women were $74 \%$ (CI 61 to 87 ), $95 \%$ (CI 89 to 102 , p $<0.05$ ), and $84 \%$ (CI 74 to 95), respectively. In patients with previous myocardial infarction, the sensitivity, specificity, and accuracy of DSE for the diagnosis of infarct-related artery stenosis in men were 64\% (CI 56 to 71 ), $87 \%$ (CI 81 to 92 ), and $68 \%$ (CI 61 to 75 ); in women these were $66 \%$ (CI 53 to 79), 94\% (CI 87 to 101), and $75 \%$ (CI 63 to 86), respectively. Sensitivity, specificity, and accuracy of DSE for the diagnosis of remote coronary artery stenosis in men were $72 \%$ (CI 56 to 79 ), $80 \%$ (CI 74 to 86), and $75 \%$ (CI 68 to 82); for women it was $75 \%$ (CI 63 to 87), 89\% (CI 80 to 97), and $84 \%$ (CI 74 to 94 ), respectively. The sensitivity, specificity, and accuracy of DSE for the overall and regional diagnosis of CAD in all patients are shown in Table V. Overall specificity of DSE was higher in women $(p=0.04)$. Regional accuracy was higher in women than men in the LCX and RCA regions ( $p<0.05$ in both) but not in the LAD region. Regional accuracy of DSE in the 3 arterial regions 
TABLE II Hemodynamic Data of Men and Women Undergoing Dobutamine-Atropine Stress Echocardiography

\begin{tabular}{|c|c|c|c|}
\hline $\begin{array}{l}\text { Hemodynamic and Stress } \\
\text { Test Variables }\end{array}$ & $\begin{array}{c}\text { Men } \\
(n=210)\end{array}$ & $\begin{array}{l}\text { Women } \\
(\mathrm{n}=96)\end{array}$ & $\mathrm{p}$ Value \\
\hline Heart rate at rest (beats/min) & $70 \pm 13$ & $71 \pm 14$ & NS \\
\hline Heart rate at peak stress (beats/min) & $135 \pm 18$ & $134 \pm 15$ & NS \\
\hline $\begin{array}{l}\text { Systolic blood pressure at rest } \\
(\mathrm{mm} \mathrm{Hg})\end{array}$ & $128 \pm 20$ & $131 \pm 24$ & NS \\
\hline $\begin{array}{l}\text { Systolic blood pressure at peak stress } \\
\text { (mm Hg) }\end{array}$ & $135 \pm 27$ & $138 \pm 27$ & NS \\
\hline Rate-pressure product at rest & $9,021 \pm 2,394$ & $9,406 \pm 2,991$ & NS \\
\hline Rate-pressure product at peak stress & $18,140+4.187$ & $18,543 \pm 4.223$ & NS \\
\hline $\begin{array}{l}\text { Maximum dobutamine dose } \\
(\mu \mathrm{g} / \mathrm{kg} / \mathrm{min})\end{array}$ & $38.4 \pm 74$ & $36.9 \pm 7$ & 0.03 \\
\hline Atropine given & $113(54)$ & $39(41)$ & 0.03 \\
\hline ST-segment depression & $63(30)$ & $22(23)$ & 0.2 \\
\hline
\end{tabular}

TABLE III Reasons for Termination of Dobutamine Stress Testing in Men and Women

\begin{tabular}{|lccc|}
\hline $\begin{array}{l}\text { Reasons for Test } \\
\text { Termination }\end{array}$ & $\begin{array}{c}\text { Men } \\
(\mathrm{n}=210)\end{array}$ & $\begin{array}{c}\text { Women } \\
(\mathrm{n}=96)\end{array}$ & $\mathrm{p}$ Value \\
\hline $\begin{array}{l}\text { 85\% of maximum heart } \\
\text { rate }\end{array}$ & $137(65)$ & $81(84)$ & $<0.001$ \\
$\begin{array}{l}\text { Maximum dose } \\
\text { Angina }\end{array}$ & $21(10)$ & $3(3)$ & 0.03 \\
$\begin{array}{l}\text { ST changes } \\
\text { Arrhythmias }\end{array}$ & $29(14)$ & $7(7)$ & 0.1 \\
$\begin{array}{l}\text { Hypotension } \\
\text { Chills, flushing, anxiety, } \\
\text { dizziness }\end{array}$ & $6(3)$ & 0 & 0.1 \\
\hline \multicolumn{2}{l}{ Data are expressed as mean \pm SD or number of patients (\%). } & \\
\hline
\end{tabular}

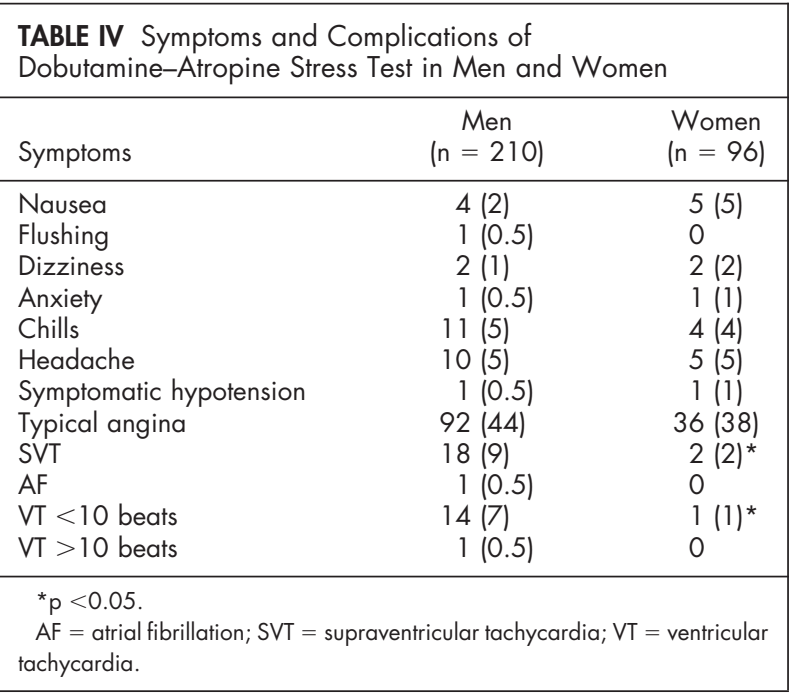

pooled together was higher in women than in men ( $\mathrm{p}$ $<0.005$ ).

Comparison of echocardiography and electrocardiography: Among 177 men with an interpretable electrocardiogram, ischemic electrocardiographic changes occurred in 58 of 144 patients with and in 5 of 33 patients without CAD (sensitivity $=40 \%$ [CI 33 to 48], specificity $=85 \%$ [CI 79 to 90], and accuracy $=$
49\% [CI 41 to 56]). Echocardiography was more sensitive and accurate than electrocardiography $(p<0.00001$ for both sensitivity and accuracy). Among 88 women with an interpretable electrocardiogram, ischemic electrocardiographic changes occurred in 16 of 57 patients with and in 6 of 31 patients without significant $\mathrm{CAD}$ (sensitivity $=$ $28 \%$ [CI 19 to 37], specificity $=81 \%$ [CI 72 to 89 ], and accuracy $=47 \%$ [CI 36 to 57], p = NS vs men). Echocardiography was more sensitive and accurate than electrocardiography $(\mathrm{p}$ $<0.00001$ for both sensitivity and accuracy).

\section{DISCUSSION}

This is the first study that evaluates the safety, feasibility, hemodynamic profile, and accuracy of DSE for the diagnosis of CAD in women. Our study shows that DSE is a feasible, safe, and accurate method for the diagnosis of CAD in women with limited exercise capacity and suspected myocardial ischemia. There were no serious side effects during the dobutamine stress test and the prevalence of hypotension and minor side effects in women (dizziness, nausea, flushing, and headache) was similar with those in men. Arrhythmias were not the reason for termination of the test in any of the 96 women included in this study. Additionally, the prevalence of supraventricular and ventricular tachycardia was significantly lower in women. This may be explained in part by the lower prevalence of CAD and the better baseline left ventricular function in women than in men.

Gender differences in the accuracy of dobutamine stress echocardiography: The higher overall specificity and regional accuracy of DSE in women than in men in our study is difficult to explain. A possible explanation is the gender difference in the prevalence of CAD. ${ }^{19}$ However, the lower prevalence of CAD in women was not associated with reduced sensitivity. Women have smaller left ventricular mass and wall thickness than men. ${ }^{20}$ Myocardial regions adjacent to the fibrous skeleton of the heart (the basal regions of the posterior septum and the inferoposterior wall) may demonstrate a heterogeneity of thickening at highdose dobutamine compared with adjacent caudal segments, giving a false-positive result in the absence of significant coronary artery stenosis. ${ }^{10}$ Because men have a thicker myocardium, this heterogeneity of thickening may contribute to more false-positive tests in men than in women in whom myocardial thickness is less and heterogeneity of contraction between these regions during stress may be less evident. Another explanation is the less thick chest wall in women, which may improve imaging compared with men. It has been demonstrated that imaging quality influences the agreement on interpretation of dobutamine stress echocardiographic images ${ }^{21}$ and thereby may have an effect on the accuracy of the test. Women reached the 


\begin{tabular}{|c|c|c|}
\hline Diagnostic Parameters & Men & Women \\
\hline \multicolumn{3}{|l|}{ Overall diagnosis } \\
\hline Sensitivity & $73(67-79)$ & $76(67-84)$ \\
\hline Specificity & 77 (71-83) & $94(89-99)$ * \\
\hline Positive predictive value & $93(90-97)$ & 94 (89-99) \\
\hline Negative predictive value & $39(33-46)$ & $68(59-77)^{\dagger}$ \\
\hline Accuracy & $74(68-80)$ & 82 (75-90) \\
\hline Sensitivity in 1-vessel disease & $56(46-66)$ & $64(53-75)$ \\
\hline Sensitivity in 2-vessel disease & $78(70-86)$ & $86(76-96)$ \\
\hline Sensitivity in 3-vessel disease & $84(77-92)$ & 100 (100-100) \\
\hline \multicolumn{3}{|l|}{ Multivessel ischemic pattern } \\
\hline Sensitivity & $53(47-60)$ & $46(36-56)$ \\
\hline Specificity & $90(86-94)$ & 97 (84-101) \\
\hline Accuracy & $70(64-76)$ & $83(76-91)^{*}$ \\
\hline \multicolumn{3}{|l|}{ LAD stenosis } \\
\hline Sensitivity & $66(59-72)$ & 68 (59-77) \\
\hline Specificity & $86(81-91)$ & $88(81-94)$ \\
\hline Accuracy & 75 (69-81) & $78(70-86)$ \\
\hline \multicolumn{3}{|l|}{ LCX stenosis } \\
\hline Sensitivity & $69(63-76)$ & $82(74-90)$ \\
\hline Specificity & $88(83-92)$ & 91 (84-97) \\
\hline Accuracy & 78 (72-84) & $89(82-95)^{*}$ \\
\hline \multicolumn{3}{|l|}{ RCA stenosis } \\
\hline Sensitivity & $60(54-67)$ & $68(58-77)$ \\
\hline Specificity & $89(85-94)$ & 92 (87-98) \\
\hline Accuracy & $73(67-80)$ & $84(77-92)$ * \\
\hline \multicolumn{3}{|l|}{ All arteries } \\
\hline Sensitivity & $65(61-69)$ & $71(65-77)$ \\
\hline Specificity & $88(85-91)$ & 90 (87-94) \\
\hline Accuracy & 75 (72-79) & $84(79-88)^{\dagger}$ \\
\hline \multicolumn{3}{|c|}{$\begin{array}{l}{ }^{*} p<0.05 ;{ }^{\dagger} p<0.005 \\
\text { Values are presented as percentage (95\% confidence interval). } \\
L A D=\text { left anterior descending. }\end{array}$} \\
\hline
\end{tabular}

target heart rate more often than men. This may explain the higher regional accuracy of DSE in women than in men. Finally, an intrinsic gender difference in myocardial response to dobutamine infusion may exist. Women may have a better response to the same dose of dobutamine than men due to a difference in the volume of distribution. In this study, women could reach the target heart rate more frequently and required atropine administration less frequently than men despite the relatively higher prevalence of therapy with $\beta$ blockers and the smaller peak dobutamine dose in women.

Comparison with previous studies: Bach et al ${ }^{10}$ reported that most of the false-positive DSE studies occurred in women. However, these authors did not report the prevalence of CAD in their study. Therefore, gender difference in the specificity of DSE could not be studied due to the lack of information regarding the true negative tests. The results of our study are aligned with previous reports, which inferred the usefulness of stress echocardiography for the diagnosis of CAD in women. ${ }^{1-3,22}$ Massini et $\mathrm{al}^{22}$ studied the accuracy of high-dose dipyridamole echocardiography in 83 women with a $47 \%$ prevalence of CAD. Echocardiography had a sensitivity of $79 \%$ and a specificity of $93 \%$. Marwick et $\mathrm{al}^{3}$ reported that in 161 women with a $63 \%$ prevalence of CAD, exercise echocardiography had a sensitivity of $80 \%$ and specificity of
$81 \%$. Roger et al ${ }^{23}$ compared the diagnostic accuracy of exercise echocardiography in men and women with suspected CAD. They concluded that in clinical practice, test verification bias in angiographic referrals results in a lower observed specificity and a higher sensitivity of exercise echocardiography. The positive predictive value and adjusted sensitivity were lower in women compared with men and the authors concluded that the difference may represent an intrinsic gender difference rather than being related to gender difference in the prevalence of the diseases.

Study limitations: Most of the study patients had a previous myocardial infarction and the prevalence of CAD was high. Therefore, these patients represent the usual patients selected for coronary angiography rather than the overall population subjected to noninvasive testing as has been demonstrated in studies of exercise echocardiography. ${ }^{23}$ It is important to conduct a similar study in a large group of patients with suspected CAD, particularly in those with the intermediated probability of CAD. Nevertheless, the trend to better specificity and accuracy of DSE in women than in men was also demonstrated in patients without previous myocardial infarction in our study. Men and women were not matched with regard to the prevalence of CAD and left ventricular function at rest. Referral bias in performing coronary angiography may have contributed to differences in diagnostic accuracy. ${ }^{23}$ However, the higher specificity of DSE in women was coupled with a high-positive predictive value despite a lower prevalence of CAD in women, which suggests an intrinsic gender difference in the response to dobutamine rather than a difference in the clinical characteristic or referral bias as the underlying reason for gender difference in specificity and regional accuracy.

1. Sawada SG, Ryan T, Fineberg NS, Armstrong WF, Judson WE, McHenry PL, Feigenbaum $\mathrm{H}$. Exercise echocardiographic detection of coronary artery disease in women. J Am Coll Cardiol 1989;14:1440-1447.

2. William MJ, Marwick TH, O'Gorman D, Foale RA. Comparison of exercise echocardiography with an exercise score to diagnose coronary artery disease in women. Am J Cardiol 1994;74:435-438.

3. Marwick TH, Anderson T, Williams J, Haluska B, Melin JA, Pashkow F, Thomas JD. Exercise echocardiography is an accurate and cost efficient technique for detection of coronary artery disease in women. J Am Coll Cardiol 1995;26: 335-341.

4. Cerqueira MD. Diagnostic testing strategies for coronary artery disease: special issues related to gender. Am J Cardiol 1995;75:52D-60D.

5. Crouse LJ, Kramer PH. Are there gender differences related to stress or pharmacological echocardiography? Am J Card Imaging 1996;10:65-71.

6. Salustri A, Fioretti PM, Pozzoli MMA, McNeill AJ, Roelandt JRTC. Dobutamine stress echocardiography: its role in the diagnosis of coronary artery disease. Eur Heart J 1992;13:70-77.

7. Sawada SG, Segar DS, Ryan T, Brown SE, Dohan AM, Williams R, Fineberg NS, Armstrong WF, Feigenbaum H. Echocardiographic detection of coronary artery disease during dobutamine infusion. Circulation 1991;83:1605-1614.

8. Ruffolo RR. The pharmacology of dobutamine. Am J Med Sci 1987;294:244248 .

9. Blomstrand P, Engvall J, Swahn E, Safstrom K, Thulesius O. Cardiovascular effects of dobutamine stress testing in women with suspected coronary artery disease. Heart 1996;75:463-468.

10. Bach D, Muller DWM, Gros BJ, Armstrong WF. False positive dobutamine stress echocardiograms: Characterization of clinical, echocardiographic and angiographic findings. J Am Coll Cardiol 1994;24:928-933.

11. Diamond G, Forrester J. Analysis of probability as an aid in the clinical diagnosis of coronary artery disease. N Engl J Med 1979;300:1350-1358.

12. Fioretti PM, Poldermans D, Salustri A, Forster T, Belloti E, Boersma E, McNeill AJ, El-Said EM, Roelandt JRTC. Atropine increases the accuracy of 
dobutamine stress echocardiography in patients taking beta-blockers. Eur Heart $J$ 1994; $15: 355-360$

13. Elhendy A, Geleijnse ML, Roelandt JRTC, van Domburg RT, Cornel JH, TenCate FJ, Postma-Tjoa J, Reijs AEM, El-Said GM, Fioretti PM. Evaluation by quantitative 99m-technetium MIBI SPECT and echocardiography of myocardial perfusion and wall motion abnormalities in patients with dobutamine-induced ST-segment elevation. Am J Cardiol 1995;76:441-448.

14. Elhendy A, Cornel JH, Roelandt JRTC, van Domburg RT, Nierop PR, El-Said GM, Fioretti PM. Relation between contractile response of akinetic segments during dobutamine stress echocardiography and ischemia assessed by simultaneous 201 thallium SPECT. Am J Cardiol 1996;77:955-959.

15. Bellotti P, Fioretti PM, Forster T, McNeill AJ, El-Said EM, Salustri A, Roelandt JRTC. Reproducibility of the dobutamine-atropine echocardiography stress test. Echocardiography 1993;10:93-97.

16. Baptista J, Arnese M, Roelandt JRTC, Fioretti P, Keane D, Escaned J, Boersma E, Di Mario C, Serruys PW. Quantitative coronary angiography in the estimation of the functional significance of coronary stenosis: Correlation with dobutamine-atropine stress test. J Am Coll Cardiol 1994;23:1434-1439.

17. Marwick TH, D'Hondt AM, Baudhuin T, Willemat A, Wijns W, Detry J, Melin J. Optimal use of dobutamine stress for the detection and evaluation of coronary artery disease: combination with echocardiography, scintigraphy or both? J Am Coll Cardiol 1993;22:159-167.
18. Elhendy A, van Domburg RT, Roelandt JRTC, Geleijnse ML, Cornel JH, El-Said GM, Fioretti PM. Accuracy of dobutamine stress echocardiography for the diagnosis of coronary artery stenosis in patients with myocardial infarction: the impact of extent and severity of left ventricular dysfunction. Heart 1996;76: 123-128.

19. Weiner DA, Ryan TJ, McCabe CH, Kennedy JW, Schloss M, Tristani F, Chaitman BR, Fisher LD. Correlations among history of angina, ST segment response and prevalence of coronary artery disease in the Coronary Artery Surgery Study. N Engl J Med 1979;301:230-235.

20. Levy D, Savage DD, Garrison RJ, Anderson KM, Kannel WB, Castelli WP. Echocardiographic criteria of left ventricular hypertrophy: the Framingham Heart Study. Am J Cardiol 1987;59:956-960.

21. Hoffmann R, Lethen H, Marwick TH, Arnese M, Fioretti PM, Pingitore A, Picano E, Buck T, Erbel R, Flachskampf FA, Hanrath P. Analysis of interinstitutional observer agreement in interpretation of dobutamine stress echocardiograms. J Am Coll Cardiol 1996;27:330-336.

22. Massini M, Picano E, Lattanzi F, Distante A, L'Abbate A. High dose dipyridamole-echocardiography test in women. Correlation with exercise electrocardiography test and coronary angiography. J Am Coll Cardiol 1988;12:682-685. 23. Roger VL, Pellikka PA, Bell MR, Chow CWH, Bailey KR, Seward JB. Sex and test verification bias. Impact on the diagnostic value of exercise echocardiography. Circulation 1997;95:405-410. 